\title{
Reflexões metodológicas para a análise sociocultural de redatores em corpora históricos
}

Célia Regina dos Santos Lopes Leonardo Lennertz Marcotulio Márcia Cristina de Brito Rumeu Alexandre Xavier Lima

\section{Resumo}

Este artigo expõe em discussão procedimentos metodológicos produtivos no processo de reconstrução dos perfis socioculturais de redatores de sincronias passadas da língua portuguesa. Pretende-se pensar a questão da aplicação de categorias sociais (gênero, faixa etária, grau de escolaridade, nacionalidade/naturalidade do autor) aos redatores de missivas manuscritas e de textos impressos, apontando os percalços e os caminhos metodológicos implementados no desenvolvimento de uma sociolinguística histórica do português.

Palavras-chave: categorias sociolinguísticas; o método na sociolinguística histórica; os corpora históricos. 


\section{Considerações iniciais}

No âmbito dos estudos sociolinguísticos de orientação laboviana (WEINREICH et alii, 1968; LABOV, 1972), a identificação de categorias sociais como gênero, idade, região e grau de escolaridade dos informantes, por exemplo, se justifica em função da relação estabelecida entre o social e o linguístico. $\mathrm{O}$ agrupamento dessas categorias constitui, assim, o perfil sociocultural dos agentes, o que proporciona ao linguista um melhor entendimento dos condicionamentos sociais de um fenômeno linguístico variável.

Quando se coloca o foco em textos escritos em sincronias passadas, o direcionamento teórico-metodológico pode ser mantido, desde que se façam as devidas ressalvas, tendo em vista, em alguns casos, a escassez de informações disponíveis para dimensionar as condições de produção destas fontes históricas.

Caso o objetivo da investigação histórica, numa perspectiva sociolinguística, seja o de descrever a produção linguística de redatores de um determinado local do Brasil, a categoria social região parece ser satisfatória, contanto que se faça um levantamento do local de nascimento desses informantes. O mesmo tipo de estudo geralmente é feito com outras categorias sociais que são reconhecidas através do próprio documento ou de fontes secundárias sobre seus redatores.

Por outro lado, essas categorias sociais, tal qual comumente as conhecemos, podem ser insuficientes em estudos que adotem uma perspectiva que considere a reconstituição da sócio-história do português no Brasil e do português brasileiro, inserida num contexto de discussão sobre a História Social da Escrita, razão pela qual torna-se pertinente repensá-las.

Não queremos dizer, contudo, que a concepção de perfil como conjunto de categorias sociais utilizadas por diversos estudos atuais esteja equivocada. No nosso modo de entender, a questão que aqui se coloca é que, de acordo com a maneira como se operacionaliza a ideia de perfil, esta pode responder apenas parcialmente aos objetivos almejados. Em nosso caso, em função das necessidades que se apresentam em trabalhos empíricos que buscam tratar da reconstituição sócio-histórica do português, é cabível o questionamento sobre o que estamos entendendo por perfil sociocultural. Em que medida falar em gênero e região, por exemplo, é dar conta da descrição de um perfil? O problema que queremos evidenciar, e que nos preocupa, é o de tomar o perfil como uma mera combinação de variáveis sociais, recortadas e concebidas como realidades estanques e com sentidos prévios ao contexto em que ocorrem.

O entendimento do perfil para a análise de corpora históricos sugere um foco privilegiado sobre o indivíduo, o que conduz obrigatoriamente a uma decisão teórica. Por que não realizar uma 
leitura da produção linguística (texto) em termos de seu contexto de produção? Por que insistir em fazê-la somente a partir do indivíduo? Se assumirmos que indivíduo e sociedade são dois conceitos que estão intimamente imbricados, não sendo, portanto, dissociáveis, até que ponto faz sentido investigar os redatores apenas em termos de seus perfis? Em outras palavras, até que ponto a caracterização individual de um informante não é simultaneamente a caracterização do grupo do qual faz parte?

Devemos ter o cuidado necessário para não tratar do indivíduo desconectado do todo. Repensar, assim, o conceito de perfil torna-se necessário, levando-se em consideração que o nosso propósito é entender a escrita a partir de quem a escreveu em um determinado contexto sócio-histórico.

Pelo que vemos, até o momento, a discussão maior que se necessita fazer é acerca dos conceitos de individual e social, de indivíduo e sociedade. Nesse sentido, nosso objetivo, aqui, é levantar questionamentos iniciais que nos permitam pensar que, para trabalhos que busquem reconstituir uma sócio-história do português, devemos pensar, em um primeiro momento, nas formas de abordagens sobre este indivíduo, as vantagens do procedimento de caracterização de seu perfil e sua pertinência para os propósitos de nossos estudos sócio-históricos. Acreditamos no potencial analítico de um cruzamento de perspectivas, que relacione a trajetória de vida dos sujeitos (que vai mais além das categorias tradicionais de perfil), o contexto de produção dos textos (em que momento foi escrito, o que foi escrito, para quem foi escrito, em que condições e com que finalidades foi escrito) e o mapeamento e descrição das redes de escrita (diálogos estabelecidos e possíveis interlocutores). Isto seguramente nos permitirá localizar a produção escrita de um indivíduo num contexto de produção mais amplo, o que, por sua vez, nos garante a possibilidade de uma conceituação alterna de perfil sociocultural.

Nesse sentido, este trabalho busca apresentar e justificar alguns procedimentos metodológicos que temos adotado em nossas pesquisas, no que se refere à identificação de perfis socioculturais de redatores de sincronias pretéritas. Relataremos as dificuldades encontradas e as decisões tomadas para a aplicação de categorias sociais aos redatores tanto de textos manuscritos, quanto de textos impressos, assim como a relevância de proceder tais abordagens para o objetivo maior da investigação na temática mencionada.

A seguir, apresentaremos notícias de diferentes experiências metodológicas que têm sido desenvolvidas mais afins com a perspectiva aqui discutida. Estamos conscientes de que a não homogeneidade de nosso texto é uma prova de que essa discussão deve ser realizada. 
Notícias de metodologias utilizadas para a identificação de perfis socioculturais de redatores de textos manuscritos

No que se refere às metodologias que aqui serão descritas para os textos manuscritos, constamos de dois estudos específicos que versam sobre a análise das formas de tratamento. Tais estudos foram realizados a partir de cartas, o que nos exige que, em função do fenômeno linguístico escolhido e do gênero textual em questão, se proceda não só à identificação dos perfis socioculturais dos redatores (missivistas), assim como dos destinatários das trocas interativas.

A opção pelo estudo diacrônico a partir de um corpus constituído por cartas não é gratuita. A carta, como gênero discursivo primário (BAKHTIN, 1997), configura-se como uma circunstância espontânea de comunicação verbal. Estruturada em um eixo que pressupõe um autor, um destinatário e um tema-íntimo, a carta-missiva segue um padrão composicional reconhecido há muito no mundo ocidental. Em geral, o local, a data, a saudação inicial, o corpo do texto, a despedida e a assinatura estão sempre presentes. São essas propriedades características da carta que permitem a identificação do perfil sociocultural do remetente na sua relação com o destinatário. Apesar das aparentes vantagens desse gênero, as cartas não reproduzem dados de fala. Este é, sem dúvida, um problema fundamental que se tem procurado minimizar nos estudos de linguística histórica, perpetuado na máxima laboviana da "arte de fazer o melhor uso de maus dados" (LABOV, 1994, p.11) ou, melhor dizendo, "fazer um bom uso dos dados disponíveis".

A carta é um tipo de fonte documental que permite mais facilmente identificar as categorias sociais tradicionalmente conhecidas pelos que levam em conta o modelo sociolinguístico laboviano. A partir dela e com as informações composicionais do próprio gênero inicia-se o trabalho de garimpo para a identificação da origem do remetente, sua idade, seu nível sociocultural e papel social assumido em determinado contexto histórico. Além disso, a carta pessoal, por exemplo, pelo seu caráter mais íntimo ou espontâneo, pode facilitar a identificação de fatos linguísticos em processos de mudança. É preciso ter mente, entretanto, que se, por um lado, a carta transmite a inovação e mudança linguísticas, por outro, conserva fórmulas fixas em que se perpetuam "tipos relativamente estáveis de enunciados" (BAKHTIN, 1997, p. 279 apud SOTO, 2007, p. 100).

Apesar de apresentar algumas variações em sua estrutura composicional ao longo do tempo, as cartas se caracterizam por alguns traços prototípicos que podem interferir, sobremaneira, na análise de fenômenos linguísticos quando se parte desse gênero como fonte para o estudo da mudança linguística. Em termos da estrutura textual, o gênero epistolar, no geral, apresenta uma 
macroestrutura constituída pelas seguintes partes: a seção de contato inicial (em que costuma figurar a saudação e a captação da benevolência), o núcleo da carta (o corpo do texto, a razão pela qual a carta está sendo escrita, predominando um pedido de algo concreto, notícias ou uma ordem a ser cumprida etc.) e a seção de despedida. Nessas partes constitutivas ${ }^{1}$, principalmente na saudação houve desde a origem do gênero grande preocupação de conferir respeito aos papéis sociais e às posições de emissor e receptor, construindo laços de boa vontade com o receptor e estimulando sua cooperação (BAZERMAN, 2005 apud MARCOTULIO, 2008).

É preciso ter em mente, nesse sentido, as dificuldades de interpretação de fenômenos tipicamente "textuais" que podem mascarar qualquer descrição diacrônica. Certos usos linguísticos podem estar correlacionados ao tipo de texto em que foram localizados, uma vez que existem fórmulas fixas, estruturas relativamente estáveis ou propriedades convencionalizadas que se repetem em determinado gênero particular (LOUREDA LAMAS, 2004). Este é mais um desafio do pesquisador que se aventura na análise de fontes documentais o passado: observar até que ponto a identificação de um dado mais conservador ou inovador localizado no documento realmente evidencia uma etapa de um processo de mudança sistêmica da língua ou se trata apenas de

1 Obviamente que as partes constitutivas do gênero epistolar apresentam variações de nomenclatura em função do tempo, dos autores e dos inúmeros manuais que ganharam força no Ocidente a partir da ars dictaminis (disciplina retórica centrada na redação de cartas e documentos). Há diversos tratados da história da epistolografia (o tratado de Anônimo de Bolonha, de 1135; o de Erasmo de Rotterdam, de 1520; e o de Justo Lípsio, escrito em 1590). Os tratados epistolares se multiplicaram nos séculos XVI e XVI. Para maiores detalhes ver as obras citadas em Koch (2008), Simões (2007), Marcotulio (2008) entre outros estudos que fazem menção à história do gênero.

2 SÁ, José d'Almeida Correia de. Vice-reinado de D. Luiz d'Almeida Portugal, $2^{\circ}$ Marquês do Lavradio, $3^{\circ}$ Vice-rei do Brasil. São Paulo: Companhia Editora Nacional, 1942. uma peculiaridade daquele tipo de texto.

Marcotulio (2008) trabalhou com cartas do Marquês do Lavradio, português e vice-rei do Brasil, escritas no Rio de Janeiro no terceiro quartel do século XVIII a diferentes destinatários. As cartas de Lavradio, que se encontram no Arquivo Nacional do Rio de Janeiro, chamam a atenção não só pela quantidade, mas também pelo grande número de relações sociais existentes. Além de ser um rico material para análises linguísticas, estas cartas também despertam o interesse de historiadores e outros pesquisadores interessados no Brasil Colônia, pelas valiosas informações veiculadas.

Quanto à metodologia utilizada para a identificação e caracterização do perfil sociocultural do remetente das cartas, como se trata de um personagem ilustre, os dados biográficos não resultaram de difícil alcance. Além de dicionários de famílias portuguesas, dicionários sobre personagens e momentos importantes do Brasil Colônia e de grandes enciclopédias portuguesas e brasileiras, o autor ainda contou com diversos títulos da historiografia luso-brasileira que retratam o período em questão, assim como uma biografia do Marquês do Lavradio produzida por um de seus descendentes, o $6^{\circ}$ Marquês do mesmo título². Assim, informações como idade, grau de instrução, data de nascimento, local de nascimento, razão pela qual foi escolhido para o posto de vice-rei e informações relativas ao recebimento do título de Marquês do Lavradio foram facilmente obtidas. 
A consulta às fontes secundárias permitiu que Marcotulio (2008) percebesse a existência de uma problemática histórica sobre a questão das hierarquias político-administrativas no Brasil Colônia, na qual as cartas encontradas apresentavam-se como mediadoras de conflitos estabelecidos. Desde uma perspectiva teórica, o rei de Portugal tinha o vice-rei do Brasil como uma figura que representava a extensão do poder régio na Colônia e, por essa razão, esse seria o poder máximo na América Portuguesa. O vice-rei do Estado do Brasil estaria, assim, subordinado somente à Coroa, ao passo que todos os governadores e capitães-generais das capitanias do Brasil estariam, por sua vez, subordinados ao vice-rei. Entretanto, na prática, não era assim que o sistema funcionava. Com o intuito de garantir que o poder predominasse no lado europeu do Atlântico, o rei D. José I, através das atuações do Marquês de Pombal, não deixava claros os limites da atuação de Lavradio. Essa indefinição em torno do poder que detinha o vicerei permitia a leitura de que o vice-rei somente seria responsável por sua capitania, no caso o Rio de Janeiro, por essa ser a nova sede da Colônia a partir de 1763, e pelas capitanias subordinadas a essa, e não toda a extensão da Colônia. Dessa forma, o rei não perdia totalmente o controle da situação, uma vez que não depositava o poder em únicas mãos. Tanto o vice-rei, quanto os governadores e capitães-generais ficavam, assim, subordinados à Coroa.

Nesse sentido, ocupar a posição de vice-rei no Brasil Colônia não isentava o seu titular de relações perenes marcadas pela tensão e pelos conflitos, o que representaria uma possível posição de desconforto. Ser detentor de um título que teoricamente conferia poderes, sem, contudo, exercê-los de fato, representava estar em uma constante zona de conflitos, em que todos os atos deveriam ser criteriosamente medidos para que os interesses fossem garantidos. Essa era a situação vivenciada pelo Marquês do Lavradio em sua gestão como representante da Corte na América Portuguesa.

Esse quadro subjacente de relações e de tencionamento político circunscreve o eixo central do trabalho de Marcotulio (2008). Na busca de evidências linguísticas que permitissem um melhor entendimento dessa problemática, o autor optou por estudar as formas de tratamento que eram utilizadas por Lavradio, em cartas a diferentes destinatários da esfera pública, por acreditar que elas fornecem indícios de como as relações entre formas linguísticas e papéis sociais se construíram ao longo dos tempos. Para tanto, de modo a obter resultados mais confiáveis, Marcotulio (2008) decidiu analisar, também, as formas de tratamento encontradas nas cartas familiares, de modo a atestar se haveria a presença, no âmbito privado, de um personagem político.

Essas informações permitiram que o autor realizasse um recorte histórico a partir do qual foram selecionados os destinatários que participassem da cena, isto é, que ocupassem algum posto político-administrativo no Império luso-brasileiro. A caracterização 
social dos destinatários também foi possível através da consulta a fontes secundárias. As cartas foram escolhidas sob a condição de que veiculassem alguma informação relativa à política/modo de governar no Brasil Colônia, para que estivessem evidentes os limites do poder do vice-rei no trato com seus interlocutores. A partir daí, o autor analisou, desde uma perspectiva sociopragmática (BROWN \& LEVINSON, 1987), como as formas de tratamento poderiam atuar, nos diferentes eixos hierárquicos sociais, como estratégias de atenuação a favor da polidez linguística, contribuindo para o trabalho de construção das faces dos participantes da interação.

Quanto ao âmbito privado, não foi tarefa fácil a seleção dos destinatários. Em princípio, através de uma rápida consulta às cartas pessoais do Marquês do Lavradio, pareceu simples a escolha de alguns dos membros de sua rede familiar, uma vez que o grau de parentesco encontrava-se explícito na seção de contato inicial de cada carta, como em: "Meu Irmaõ, eSenhor domeuCoração"s. Dessa forma, aparentemente, se poderia saber qual era a relação familiar estabelecida entre o remetente e o destinatário. Entretanto, analisando outras cartas, Marcotulio (2008) verificou que as relações de parentesco indicadas pelos rótulos usados por remetente e destinatários, em muitos casos, não correspondiam à realidade histórica, uma vez que subvertiam / ampliavam os limites dos laços familiares tais como são conhecidos hoje, como o fato de chamar os genros de "filhos", a sogra de "mãe" etc., observado no seguinte excerto da carta do Marquês do Lavradio destinada ao seu tio D. Tomás de Almeida, em 20 de fevereiro de 1770: "eultimamente euRecomendo aVossaExcelência | este negoçio com aquelle ardor comque VossaExcelência deve supor | eu meintereço hoje por huns genroz, ó para melhor dizer filhos | que asestimaveis Serconstançias, que atodoz ouso Repetir dellez, | os fazem ser inseparaveis domeuCoraçaõ."

Nesse sentido, foi necessário que o conceito de família fosse lido não somente como um grupo ligado ao casamento, à consanguinidade e à coabitação, mas, como sugere Moraes Silva, em seu dicionário de 1789, como núcleo familiar, parentes e aliados, uma vez que, durante o século XVIII, "o sentimento de pertencer a uma família ultrapassava, portanto, os laços consanguíneos e se manifestava entre os parentes rituais e aliados" (VAINFAS, 2000, p. 216). Mais do que família, as relações de Lavradio com os "parentes" tinham ligação com as questões da Casa Nobiliárquica, muito mais pertinentes do que o conceito de família. Os próprios casamentos de suas filhas, comentados em algumas cartas, eram estratégias para se garantir prestígio e riquezas para a Casa Lavradio perante os nobres da Corte.

Tornou-se necessária, assim, a elaboração da genealogia dos

Carta destinada ao Conde de São Vicente, em 23 de junho de 1770 . destinatários do Marquês do Lavradio, para que houvesse uma maior fidedignidade na análise das relações. Remontou-se, então, 
4 Dr João Pedreira do Couto Ferraz e Zélia Pedreira de Abreu

5 O patriarca da família Pedreira Ferraz - Magalhães é o informante do gênero masculino, João Pedreira do Couto Ferraz, nascido no Rio de Janeiro, a 10 de agosto de 1826. Filho do casal Guilhermina Amália Correia de Lima Pedreira e Luís Pedreira do Couto Ferraz que, servindo como Desembargador Afranista da Relação, residiu na Corte, onde constituiu família composta por sete filhos. Um dos seus filhos é o missivista João Pedreira do Couto Ferraz que iniciou a sua carreira política a partir da advocacia, bacharelando-se, em 1848, na Academia de Olinda. Foi nomeado, ainda jovem, pelo Imperador Dom Pedro II, Moço da Câmara, promovido Veador da Casa Imperial e, por mais de 50 anos, exerceu a função de Secretário do Supremo Tribunal Federal. Difundiram-se, em família, formas específicas de tratamento do Conselheiro Dr. João Pedreira do Couto Ferraz como Conselheiro Pedreira, Dr. Pedreira ou Pai Pedreira. a sua estrutura social familiar, de modo a estabelecer o condicionamento das formas linguísticas a partir dos diferentes graus de parentesco. Assim sendo, considerou-se como pertencente à esfera privada somente aqueles que tivessem alguma ligação familiar com o Marquês do Lavradio, direta ou indiretamente, sendo a relação formada por laços consanguíneos ou por laços afetivos.

A questão da identificação de categorias sociais, como a idade, o gênero, o grau de parentesco, o nível cultural e o tipo de relação estabelecida entre os informantes, também é uma preocupação de Rumeu (2008) que fornece, entre outros aspectos, passos metodológicos para a identificação dos perfis socioculturais dos redatores brasileiros das epístolas familiares trocadas entre os entes da família Pedreira Ferraz-Magalhães na realidade sócio-histórica de fins do Oitocentos e na $1^{\mathrm{a}}$ metade do Novecentos.

Idas constantes ao Arquivo Nacional do Rio de Janeiro propiciaram-lhe o contato com um conjunto de cartas familiares produzidas por integrantes das ilustres famílias Pedreira Ferraz-Magalhães. A relevância desse material reside na real possibilidade de reconhecimento da história da vida privada de uma família brasileira nascida no Rio de Janeiro que circulou da capital carioca para outros espaços sociogeográficos dentro e fora do Brasil. Uma família religiosa que, apesar dos deslocamentos advindos da pressão social da vida adulta, se manteve unida pelas cartas ativas e passivas trocadas entre seus membros ao longo das suas vidas.

Em termos metodológicos, foi possível o meticuloso resgate das categorias sociais de cada um dos autores dos documentos, bem como o dos destinatários das cartas, tendo em vista a idade, o gênero, o grau de parentesco, o nível cultural e o tipo de relação familiar estabelecida entre os "informantes", detectando, pois, as redes sociais engendradas nesse jogo discursivo de intimidade familiar. A reconstrução da história privada da família Pedreira Ferraz Magalhães se deu basicamente a partir da consulta a dois livros escritos por um dos filhos do casal progenitor da família Pedreira Ferraz - Magalhães (PEDREIRA DE CASTRO, 1943; PEDREIRA DE CASTRO, 1960) e aos registros escritos nos quais havia referências às datas de nascimento e falecimento dos membros da família em análise, mais especificamente dos filhos do casal ${ }^{4}$. Ainda em relação às fontes secundárias, mostrou-se muito útil a consulta ao Dicionário das Famílias Brasileiras (BUENO \& BARATA, 2001) para checar as informações sobre as datas de nascimento e falecimento do progenitor da família (o Dr. João Pedreira do Couto Ferraz5), assim como para averiguar informações sobre a história de vida deste informante (BLAKE, 1902): grau de escolarização e atividades profissionais por ele exercidas no Brasil Império.

Esse grau de refinamento de amostras de textos produzidos por informantes seguramente identificados em relação à sua origem brasileira e ao seu nível de escolaridade (culto) permitiu a confecção 
de um estudo de painel (LABOV, 1994) para sincronias passadas em que foi possível resgatar a progressão da mudança linguística (a implementação de Você no sistema pronominal do Português Brasil) em função da análise do comportamento linguístico do indivíduo, através da sua produção escrita, em distintas faixas etárias da sua vida (juventude, adultez e velhice). A opção pela análise de cartas familiares é justificada por se tratar de um gênero textual cujo grau de formalismo é menor, visando à estruturação de uma investigação com uma maior probabilidade de expressão dos contextos linguísticos favoráveis ao aparecimento de formas nominais e pronominais de tratamento no Português Brasileiro.

Rumeu (2008) confeccionou um estudo de painel, nos moldes Labovianos (1994), em virtude do conjunto de textos que tinha em mãos: cartas familiares produzidas por brasileiros cultos de uma mesma família no decorrer de suas vidas cujos perfis socioculturais foram identificados. Foram as amostras de cartas que apontaram para o tipo de estudo sociolinguístico mais produtivo: estudo de painel voltado para a diacronia. Ficou-se à mercê do que resistiu à ação do tempo no interior dos arquivos públicos, confirmando a argumentação de Labov (1994) em relação a esse ser um dos percalços na vida do linguista-pesquisador que se volta para estudos sociolinguísticos diacrônicos.

A construção de uma sociolinguística histórica do Português Brasil, nos moldes de Lobo (2001), com base na reconstituição da história de vida dos informantes (missivistas), corrobora o controle das díades que sustentam a dinâmica das cartas pessoais trocadas no seio da família Pedreira Ferraz - Magalhães. As díades controladas evidenciam as relações familiares travadas entre pais e filhos, entre avô e netos, entre irmãos, entre tia e sobrinhos e entre amigos como remetentes e destinatários das missivas da família Pedreira Ferraz - Magalhães.

Ainda em relação aos procedimentos metodológicos adotados para o trabalho com textos de sincronias passadas, algumas questões suscitadas pela análise dessas cartas se mostraram relevantes: O que é ser um informante culto, em fins do séc. XIX e na $1^{\mathrm{a}}$ metade do séc. XX? O que é ser um padre ou uma freira nesse contexto sócio-histórico do Brasil? Quais são os seus papéis sociais vinculados a ordens religiosas engajadas em trabalhos voltados para a educação no Brasil e no exterior? Qual é a função social da mulher (mãe e esposa) e também da mulher religiosa, na sociedade brasileira oitocentista e novecentista?

No que se refere à íntima relação entre as categorias gênero e faixa etária dos informantes conjecturadas por Labov (1994, 1972 [2008]), o foco metodológico do estudo de painel voltou-se para as seguintes questões: a variável gênero poderia representar um fator de progressão (avanço) ou de regressão (retrocesso) na direção da implementação de uma nova variante (Você) no sistema linguístico? A opção por Tu ou por Você na trajetória linguística da vida 
dos informantes estaria correlacionada ao papel social assumido por homens e mulheres na realidade sócio-histórica e linguística do Português Brasileiro oitocentista e novecentista? A discussão dessas questões sociais guiou a interpretação dos resultados quantitativos da análise de painel para sincronias passadas do PB. Nesse sentido, Rumeu (2008) pensa ter esclarecido, com base em Lavov (1972 [2008, p. 326]), o seguinte: (“(...) uma compreensão plena da mudança linguística exigirá várias investigações que não estão intimamente ligadas ao quadro social, assim como outros estudos que mergulhem na rede dos fatos sociais. (...)").

Esse mergulho na rede de fatos sociais a que Labov se refere é justamente a análise linguística com base na confecção de uma metodologia de pesquisa que conduza à depreensão do perfil sociocultural dos informantes.

\section{Notícias de metodologias utilizadas para a identificação de perfis socioculturais de redatores de textos impressos}

Os textos impressos vinculados aos periódicos também impõem desafios para a construção de corpora, não apenas pelas condições de transcrição, mas, sobretudo, na identificação dos perfis dos informantes. A complexidade da estrutura está intimamente associada à complexidade da sociedade. Se grupos sociais, por meio de categorias sociais, instituem uma língua, poderíamos identificar estruturas linguísticas ou epilinguísticas que revelam esses perfis. Com o testemunho que nos restou, o registro escrito, surgem algumas questões que norteiam os trabalhos com corpora diacrônicos: Quais são as pertinentes categorias sociais presentes em outras sincronias? Qual a forma que tomam na língua? O que revelam sobre o falante?

Justifica-se o trabalho histórico com impressos ao lado dos manuscritos pelo fato de terem servido de modelo de erudição para o século XIX. Como Lima (2010) procurou ratificar, os impressos em periódicos faziam parte do cotidiano do carioca. Jornais, como a Gazeta de Noticias, publicavam cerca de 17 mil cópias e ainda circulavam em saraus da sociedade do Rio de Janeiro. As diversas seções nos jornais (Folhetins, Avisos, Publicações a Pedido etc.) entretinham, informavam e formavam os redatores/leitores da época.

Um esforço diferenciado é necessário, a começar pela tarefa de localização dos periódicos. Não são muitos acervos que guardam periódicos antigos e, às vezes, por condições naturais, o material encontra-se deteriorado. No Rio de Janeiro, contamos com o acervo da Biblioteca Nacional que reúne periódicos antigos de todo Brasil.

Localizado o material, os principais desafios para a caracterização dos perfis dos informantes são a identificação da autoria, $d a$ escolaridade e da origem do redator, a ausência de original preservado e de 
informações sobre o alcance dos textos, condições essenciais para realizar qualquer afirmação sobre a norma pertencente àquele grupo.

$\mathrm{Na}$ etapa de levantamento de textos para a formação dos corpora, longas listas de material se formam devido à quantidade de periódicos que surgiram a partir das primeiras décadas do século XIX. Os periódicos surgiam rapidamente, como também desapareciam, acompanhando as ideologias em um momento de extrema instabilidade política. Jornais diários, de tema geral, com ampla circulação, são sempre candidatos ideais para compor os corpora. Contudo, além do veículo, deve-se optar por um gênero vinculado ao periódico.

Lima (2010) optou pelas crônicas folhetinescas de França Junior. Tais crônicas são um importante testemunho da vida da nascente burguesia carioca dos oitocentos. Descrevem e ditam costumes, como também servem de modelo para outros redatores/leitores que faziam parte das redes de leitura e escrita daquele período. A localização desse informante é o resultado de um longo exercício filológico, em que foram necessárias visitas a diversos acervos, levantamento no acervo geral e busca na seção de periódicos da Biblioteca Nacional. Desse expediente, localizou-se o livro Folhetins (1878) de França Junior, coletânea de folhetins (crônicas) publicados na Gazeta de Noticias. Até chegar a esse informante e a esse jornal, tateou-se em cada periódico, identificando folhetins e, o mais difícil, identificando os autores desses textos.

No século XIX, era comum os autores não se identificarem nos seus trabalhos, ou lançarem mão de codinome ou pseudônimo. No periódico Gazeta de Noticias (1877), além de França Junior, havia outros colaboradores da seção Folhetim. Quase todos usavam codinome, como, Tralgadabas, Nemo, Prouhdome, Varuna; ou abreviavam algum nome importante para a identificação, como, Luiza B., S. Saraiva etc. Alguns ainda usavam pseudônimos, dificultando ainda mais a identificação. O que provavelmente era sabido por todos, como J.X.F.S., ocultou-se com o tempo. A saída para esses casos tem sido observar se há alguma publicação com o mesmo nome, ou se há algum outro testemunho (anúncio de venda de livro, comentário de outro cronista, notícia) no periódico que permita identificar o autor. Quando não encontramos nenhuma outra referência, somos obrigados a descartar os informantes.

Embora encontrar outra publicação de um redator não seja condição para identificarmos sua origem, sua escolaridade e outras informações sociais, geralmente, encontram-se dados biográficos de redatores justamente naqueles redatores que foram expoentes em seu tempo e deixaram uma contribuição significativa para a sociedade que faziam parte. É o caso de França Junior. O autor tem uma extensa colaboração nos jornais, exerceu funções públicas, escreveu peças de teatro e conta com várias edições de seus textos folhetinescos ainda em seu tempo, tanto em outros jornais, como também em livro (LIMA, 2010), prova de que seu texto alcançou 
uma considerável repercussão na época. Se o texto fez sucesso, era sinal de que poderia servir de modelo para outros redatores.

Contudo, o que se tem hoje é o periódico. Não se têm as provas dos jornais, muito menos os manuscritos. Não se sabe como realmente França Junior escreveu. A ausência do original faz com que se estabeleça a diferença do autor França Junior e do redator França Junior, que podem ser a mesma pessoa, como podem ser entidades diferentes. $\mathrm{O}$ autor é o criador da obra manuscrita, enquanto o redator é o responsável pela sua apresentação final vinculada a algum suporte. Assim, o informante em questão é o redator França Junior, pois só se tem o produto final de sua criação, o que também é importante, uma vez que o leitor só tinha acesso a esse produto. A distinção entre autor e redator poderia ser desfeita com a comparação de impressos e manuscritos. No entanto, ainda não foram localizados manuscritos de França Junior.

Barbosa (2005) parece ter encontrado uma maneira de aproveitar os testemunhos desses informantes cujos perfis socioculturais desconhecemos. Primeiro é necessário criar corpora com o maior número possível de informantes reconhecidamente eruditos. Depois, identificar um critério objetivo de erudição e conseguir mensurá-lo. A seguir, usar esse material como parâmetro de erudição. Para isso, Barbosa pensou na latinização da grafia, uma vez que havia, no século XIX, uma exacerbação desse modelo de escrita. Quanto mais latinizada a escrita, mais erudito seria o redator. Se também fosse possível, seria pertinente encontrarmos um fenômeno sintático em que pudéssemos contrapor oralidade versus escrituralidade - neste caso, as formas sintética e analítica do gerúndio. Lima (2010) colabora e ratifica a metodologia, quando levanta mais um informante (França Junior) para compor o parâmetro de erudição e testa a metodologia nos folhetins desse autor.

Os resultados acenam positivamente para esse recurso que tenta superar a aparente escassez de fontes confiáveis para a reconstrução histórica da norma carioca em sincronias passadas.

\section{Considerações finais}

A discussão sobre a relevância da composição do perfil sociocultural de redatores de sincronias passadas permite tecer duas breves reflexões:

$\left.1^{a}\right)$ Tanto nas cartas produzidas pelo marquês do Lavradio, subsidiando a análise do condicionamento das formas nominais de tratamento a partir dos diferentes níveis hierárquicos e dos graus de parentesco dos informantes, quanto nas cartas pessoais da família Pedreira FerrazMagalhães, fundamentando o estudo da variação das formas pronominais $T u$ e Você, voltou-se o foco para a conexão entre as formas linguísticas e a função social do informante. É claro que esse encaminhamento não 
foi ingênuo, uma vez que se queria defender a ideia de que a língua é movida pelo social. Nesse sentido, se faz necessário repensar a validade da aplicação exclusiva das categorias sociais para a depreensão do perfil sociocultural dos redatores em sincronias passadas do português, sem que se leve em conta o cenário sócio-histórico do qual os indivíduos participavam.

$2^{\mathrm{a}}$ ) Por outro lado, acredita-se que as marcas linguísticas oferecidas pelo próprio texto, como a latinização da grafia, conforme constatado por Lima (2010) em relação aos folhetins de França Júnior, podem contribuir para a identificação de perfis socioculturais de redatores através da constituição de um parâmetro objetivo para a caracterização da norma culta oitocentista, tomando-se os folhetins cariocas do século XIX como referencial de expressão dos escritores cultos.

A proposta de Barbosa (2005) de identificar um critério objetivo de erudição (a latinização da grafia) e mensurá-lo para a análise das fontes documentais se mostrou um excelente caminho de investigação. A partir desse princípio norteador definido por Barbosa (2005), podem-se utilizar, quem sabe em um futuro próximo, outros critérios (talvez não tão objetivos) como é o caso das próprias características linguísticas dos textos. Partindo do que se conhece do português brasileiro hoje, é possível organizar taxinomicamente os documentos em função da presença mais incisiva ou ausência total de traços linguísticos que apareçam como prenúncios ou vestígios do que agora sabemos configurar o português brasileiro ou uma de suas variedades (o uso do futuro perifrástico com ir + infinitivo, a presença de a gente no lugar de nós, pronome reto depois de verbos causativos, pronome $t u$ com verbo na terceira pessoa do singular, entre outros fenômenos).

\begin{abstract}
This article presents a discussion on the methodological procedures in the productive process of reconstruction of socio-cultural profiles of writers from the past synchronicities Portuguese. It is intended to reflect about the implementation of social categories (gender, age, educational level, nationality, place of birth of the author) to writers of handwritten letters and printed texts, pointing out the struggles and methodological approaches implemented in the development of a Portuguese Historical Sociolinguistic.
\end{abstract}

Keywords: sociolinguistic categories; sociolinguistic method in history; historical corpora. 


\section{REFERÊNCIAS:}

BARBOSA, A. G. “Tratamento dos corpora de sincronias passadas da língua portuguesa no Brasil: recortes grafológicos e lingüísticos". In.: LOPES, C. R. dos S. A Norma Brasileira em construção: fatos lingüísticos do século 19. Rio de Janeiro: Faculdade de Letras, UFRJ, FAPERJ. p. 25-43, 2005.

BAKHTIN, M. Os gêneros discursivos. In.: Estética da Criação Verbal. São Paulo: Martins Fontes, p. 279, 1997.

BROWN, P. \& LEVINSON, S. Politeness: some universal in language usage. Cambridge: Cambridge University, 1987.

BUENO, Antonio Henrique da Cunha.; BARATA, Carlos Eduardo de Almeida. Dicionário das Famílias Brasileiras. Volumes I e II. São Paulo. 2001.

BLAKE, Augusto Victorino Alves Sacramento. Diccionario bibliographico brazileiro. Rio de Janeiro: Imprensa Nacional, 7 Volumes. 1902. $\mathrm{KOCH}, \mathrm{P}$. "Tradiciones Discursivas y Cambio Linguístico: el ejemplo del tratamiento vuestra merced en español." In: KABATEK, Johannes (ed.) Sintaxis histórica del español y cambio linguístico: Nuevas perspectivas desde las Tradiciones Discursivas. Madrid/Frankfurt: Iberoamericana/Vervuert (Linguística Iberoamericana 31), p. 53-88, 2008.

LABOV, W. Padrões Sociolingüísticos. São Paulo: Parábola Editorial. 2008[1972].

. Principles of Linguistic Change: Internal Factors. Cambridge: Blackwell Publishers, Vol. 1. 1994.

LIMA, Alexandre Xavier. Crítica Textual e Corpora para a Linguística Histórica: Padrões Ortográficos Oitocentistas em Folhetins (crônicas) e França Junior. Volumes I e II. Dissertação (Mestrado em Língua Portuguesa) - Curso de Pós-Graduação em Letras Vernáculas. Faculdade de Letras, Universidade Federal do Rio de Janeiro, Rio de Janeiro. 2010.

LOBO, T. C. F. Para uma sociolingüística histórica do português no Brasil. Edição filológica e análise lingüística de cartas particulares do Recôncavo da Bahia, século XIX. 4 Volumes. Tese (Doutorado em Filologia e Língua Portuguesa) - Curso de Pós-Graduação da Faculdade de Filosofia, Letras e Ciências Humanas da Universidade de São Paulo. 2001, Volume II.

LOUREDA LAMAS, O. Fundamentos de una lingüística del texto real y funcional. mimeo, 2004.

MARCOTULIO, L. L. A preservação das faces e a construção da imagem no discurso politico do Marquês do Lavradio: as formas de tratamento como estratégias de atenuação da polidez lingüística. Volumes I e II. Dissertação (Mestrado em Língua Portuguesa) - Curso de PósGraduação em Letras Vernáculas. Faculdade de Letras, Universidade Federal do Rio de Janeiro, Rio de Janeiro. 2008. 
PEDREIRA DE CASTRO, Pe. Jerônimo. Zélia ou Irmã Maria do SS. Sacramento. Vida exemplar de uma mãe cristã, que terminou seus dias junto a Jesus Sacramentado. Petrópolis: Editora Vozes, VII Edição. 1960.

. Segundo Livro de Zélia (Irmã Maria do Santíssimo Sacramento). Seus escritos espirituais, cartas e exemplos. Petrópolis: Editora Vozes. 1943.

RUMEU, M. C. de B. A implementação do 'Você' no Português Brasileiro Oitocentista e Novecentista: Um Estudo de Painel. 2008. Tese de Doutorado em Língua Portuguesa - Curso de Pós-graduação em Letras Vernáculas, Rio de Janeiro: UFRJ, Faculdade de Letras. Volumes I e II. 2008.

SIMÕES, José da Silva. Sintaticização, discursivização e semanticização das orações de gerúndio no português brasileiro. Tese (Doutorado em Filologia e Língua Portuguesa) - Fac. de Fil. Letras e Ciências Humanas, Universidade de São Paulo, São Paulo, 2007.

SOTO, Ucy. M. S. Cartas através do tempo: o lugar do outro na correspondência brasileira. Niterói: EdUFF, p. 100, 2007.

VAINFAS, Ronaldo (org.). Dicionário do Brasil Colonial (1500 - 1808). Rio de Janeiro: Ed. Objetiva, 2000.

WEINREICH, U.; LABOV, W; HERZOG, M. I. Fundamentos empíricos para uma teoria da mudança lingüística. São Paulo: Parábola, 2006[1968]. 